\title{
Impression Technique of a Better Marginal Fit Auricular Prosthesis
}

\section{Theerathavaj Srithavaj ML*, Pornpattra R and Preeda W \\ Department of Prosthodontics, Mahidol University Faculty of Dentistry, Thailand}

*Corresponding author: Theerathavaj Srithavaj ML, Director Maxillofacial Prosthetic Service, Faculty of Dentistry, Mahidol University, Bangkok10400, Thailand, Tel: +66-2200-7737; +66-83-038-3366; Fax:+-662-200-7735; Email: t-kung7@hotmail.com

\section{Case Report}

Volume 3 Issue 3

Received Date: July 30, 2018

Published Date: August 10, 2018

DOI: $10.23880 /$ oajds- 16000188

\section{Abstract}

Impression of a craniofacial implants to make a definitive prosthesis may be difficult at time. Movement of facial muscles and surrounding tissue beds may be interfered with the prosthesis even if it is carefully done. Position of the patient of the patient during impression should be considered for additional technical consideration for extraoral technique for impressioning to obtain the accurate tissue around the implant site.

Procedure: By having the patient to sit up in an erect position the tissue bed had change in position and the impression can be making.

Result: the definitive wax-up and tried-in were more accurate on the skin fitness than the supine position in this case. The optimal outcome revealed that the close fit of definitive prosthesis has a closed fit margins with the surrounding tissue bed with the auricular prosthesis.

Conclusion: There are many type of movable tissue bed move and non-movable for the cranio-facial defect patient, it is essential to determine the surrounding tissue surround the defect area prior to make an impression to eliminate any technical errors for any prosthesis that required to be made. This case is an example of the selection of the position of a patient and the technical impression methodology to obtain the best possible outcome for the patient.

Keywords: Ear Prosthesis; Open margin; Impression; Defect ear; Implant support

\section{Introduction}

The esthetic requirement of the auricular prosthesis depends upon multiple factors such as color matching, correct anatomical, suitable location, and good marginal seal [1,2]. An opened margin of prosthesis usually occurred when there is movement of the head at multiple postures [3]. Another factor is the impression technique which plays an essential role to capture the most extreme movement of the facial and head area. Thus, this will result in a well fitted margin of the auricular prosthesis with extraoral implant supported $[4,5]$. Mucocutaneous tissue surrounding the area of the prosthesis also takes part in a seal of the margin of the prosthesis. Especially, 


\section{Open Access Journal of Dental Sciences}

when patient has normal daily life activities, an avoidance of opening margin may be expected in some patient. There are many techniques proposed when performing an impression in the auricular region reported in many literatures [3-6].

Position of the patient during making an area of impression should be preform prior to any procedure. The distortion of the tissue bed around the area of impression may occur when patient is laying down, due to the weight of the impression materials. Thus, the ideal position should be when patient's position at erect position. This will compensate the gap that occurs between skin-prosthesis interfaces, especially anterior margin. Thus, the weight of the impression material will not push down on to the anterior portion that has no bone support underneath the skin.

\section{Purpose}

The purpose of this impression technique was to reveal by using gelation polyvinal siloxane material, Epiform flex/solid (Dreve-Dentamid, Germany), and the erected sitting position of the patient while making an impression of the deformed auricular portion to obtain the area that was more accurate impression at a single step.

\section{Procedure}

a) Mark the position of the condyle to identify the most movable tissue bed for locating the anterior margin of the prosthesis. Patient is told to open and close the mandible as to determine the movement of the tissue. Thus, it is to identify the least movable anterior margin for the prosthesis.

b) Set the position of the patient to sitting erectedly with no head support and made the patient turn to the opposite side of the operated defect with the mouth opened.

c) Using light body gelation polyvinylsiloxane, Epiform Flex (Dreve-Dentamid, Germany) was injected the impression to passively duplicate the area around the implant coping. Then the heavy body gelation polyvinylsiloxane, Epiform Solid (Dreve-Dentamid, Germany) was injected over the light body one. Place the broken pieced wooden tough to place over the heavy body impression material as a supported matrix prior to setting.

d) Follow the laboratory procedure as Figures 1-8.

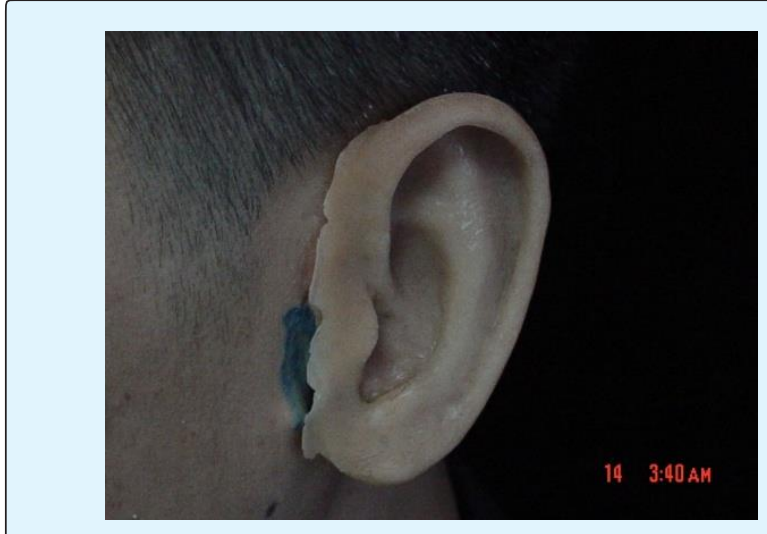

Figure 1: Previous patient's auricular prosthesis.
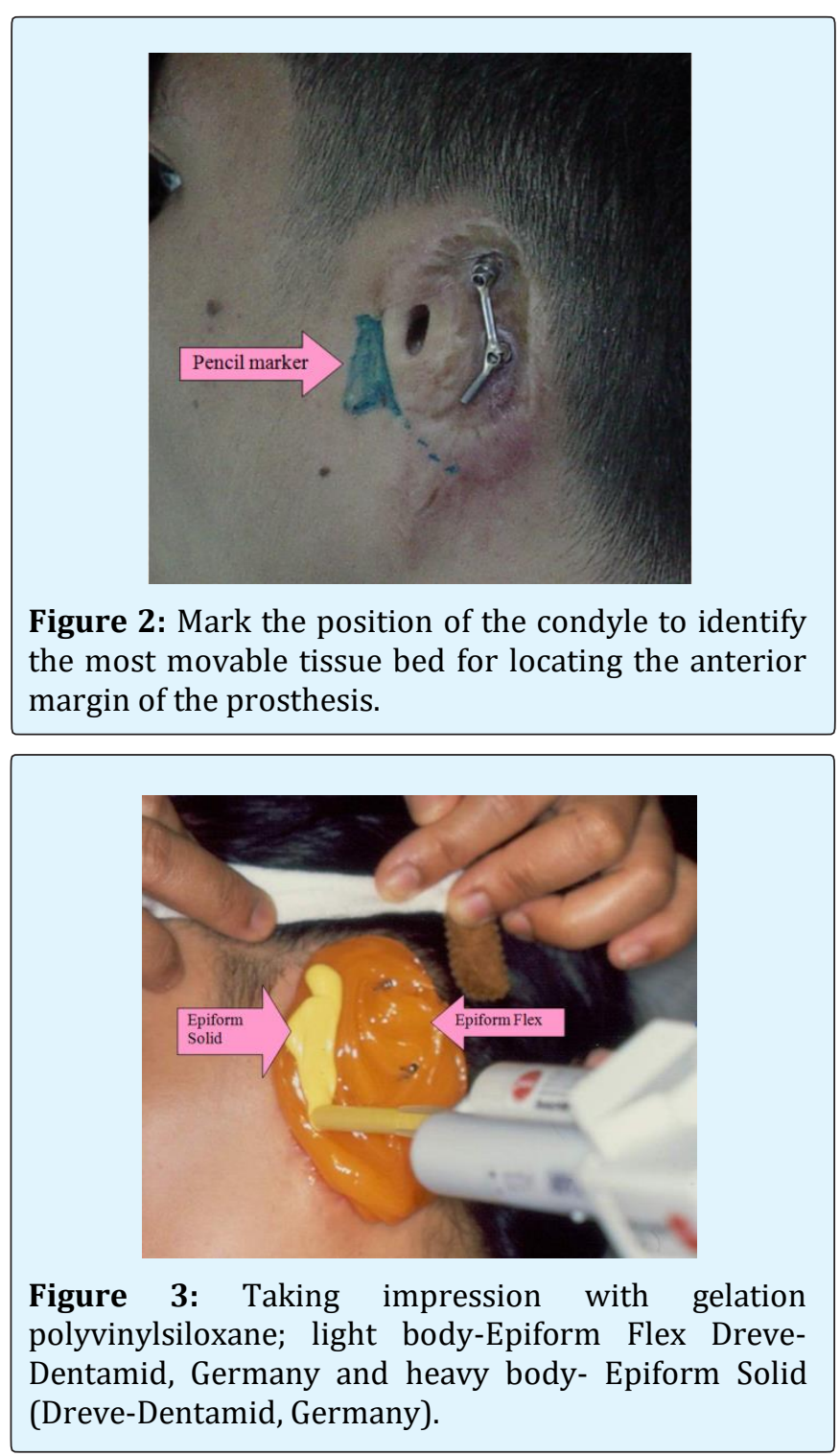


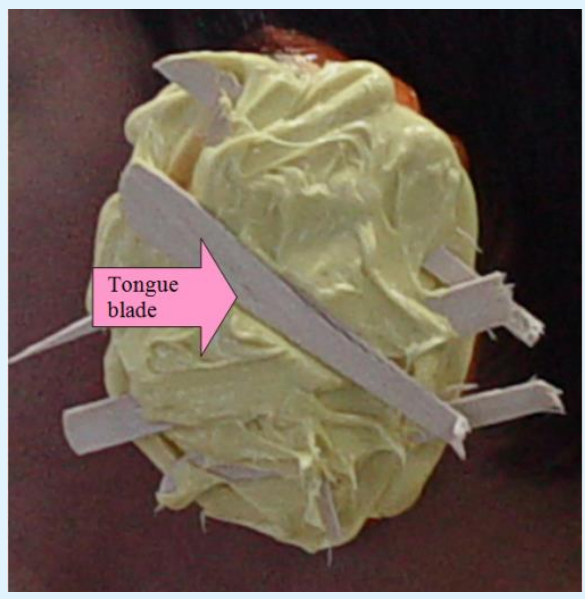

Figure 4: Impression of the area around the implant coping with the wooden pieces as a supported matrix prior to setting.

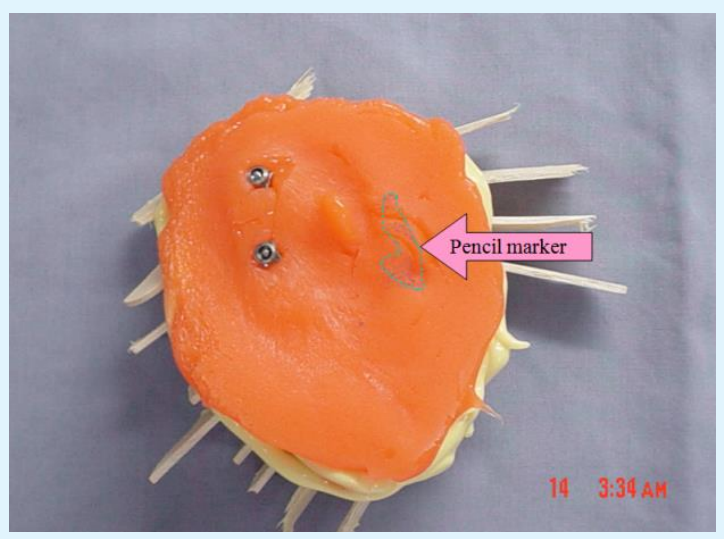

Figure 5: Tissue surface of impression with pencil marker.

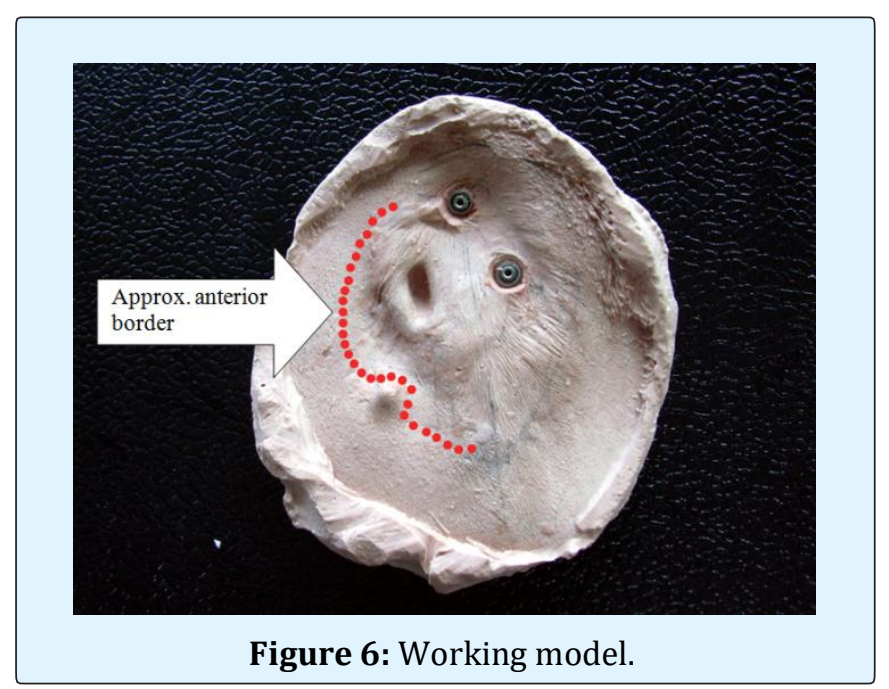

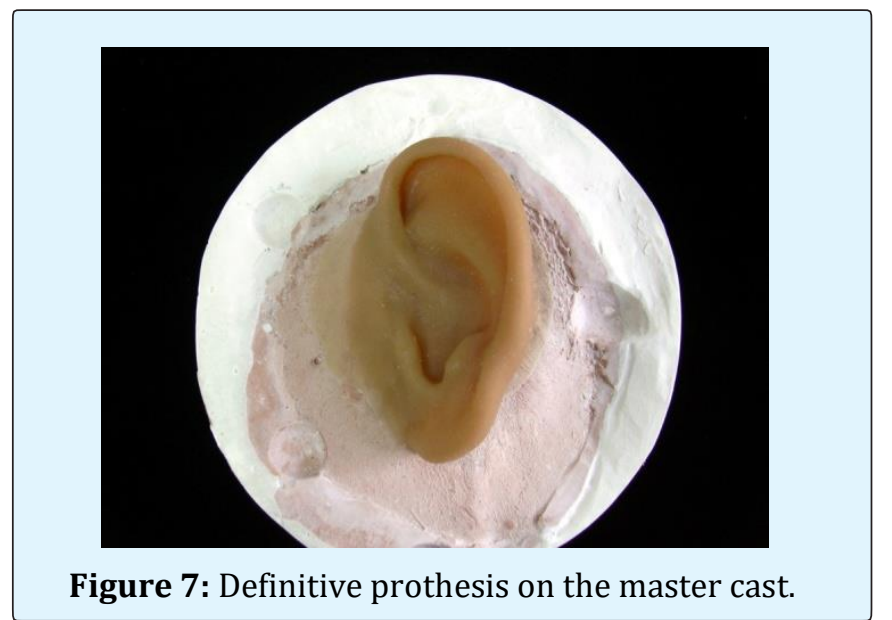

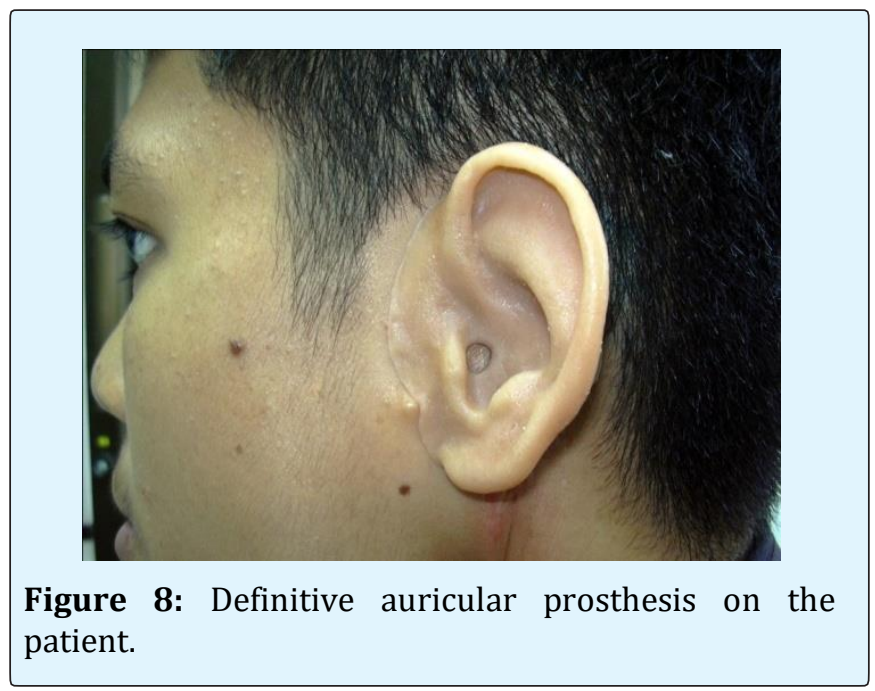

\section{Discussion}

In congenital auricular deformed patient, the use of extra-oral implant support prosthesis assists in good retentive prosthesis and easy for patient's maintenance of an auricular prosthesis. It is crucial to identify the movable tissue bed prior to impression of the defect area. The movable TMJ should be identify anterior of a planned auricular prosthesis. This technique did not require the custom tray and may reduce unavoidable pressure of the tray used. The predictable result could be obtained from this technique. However, in some cases the craniofacial abnormality from certain syndrome may have limitation of the successful result. The larger size of the craniofacial defect may need special combination impression techniques [7]. In addition, a thin margin of the prosthesis may also be used to hind the anterior margin in some difficult cases as well. 


\section{References}

1. Wolfaardt JF, Coss P (1996) An impression and cast construction technique for implant-retained auricular prostheses. J Prosthet Dent 75(1): 45-49.

2. Mathews MF, Sutton AJ, Smith RM (2000) The auricular impression: an alternate technique. J prosthodont 9(2): 106-109.

3. Kubon TM (2001) Creating an adaptable anterior margin for an implant-retained auricular prosthesis. J Prosthet Dent 86(3): 233-240.

4. Kubon TM, Kurtz KS, Piro JD (2000) Impression procedure for creating a partial auricualr prosthesis. J Prosthet Dent 83(6): 648-651.
5. Dumbrigue HB (1997) Anterior margin adaptation for implant-retained auricular prostheses. J prosthet Dent 78(4): 425-428.

6. Kubon TM, James D Anderson (2003) An implantretained auricular impression technique to minimize soft tissue distortion. J Prosthet Dent 89(1): 97-101.

7. Srithavaj T, Choteprapert N, Wijitworawong A, Hovichitr W, Sanohkann S (2006) Restoration of Large Facial Prosthesis with a connection to the Intraoral Prosthesis: A Case Report. Mahidol Dent J 26: 351-359. 